\title{
CAESAREAN SCAR ECTOPIC PREGNANCY: 2 CASE REPORTS
}

Mini Isac ${ }^{1}$, Mary George ${ }^{2}$, V. M. Jayasree Thankachi ${ }^{3}$

\section{HOW TO CITE THIS ARTICLE:}

Mini Isac, Mary George, V. M. Jayasree Thankachi. "Caesarean Scar Ectopic Pregnancy: 2 Case Reports". Journal of Evolution of Medical and Dental Sciences 2015; Vol. 4, Issue 18, March 02; Page: 3183-3188,

DOI: $10.14260 /$ jemds/2015/461

ABSTRACT: Caesarean scar ectopic pregnancy (CSEP) is one of the rarest forms of ectopic. The Incidence is rising due to increasing number of caesarean sections. Awareness of this condition and early diagnosis can improve the outcome and future fertility. In this article we discuss 2 cases of CSEP, 1 being diagnosed late and 1 diagnosed early with TVUS + MRI, managed successfully with Methotrexate.

KEYWORDS: Previous caesarean scar, ectopic pregnancy, methotrexate.

INTRODUCTION: Caesarean scar ectopic pregnancy is one of the rare forms of ectopic pregnancy incidence being 1:1800 of all pregnancies.[1] Though rare, incidence seems to be on the rise and an obstetrician is likely to encounter this entity in her lifetime. Natural history of CSEP is that it can result in uterine rupture, haemorrhage, high risk of hysterectomy, morbidity and loss of future fertility.[2]

2 cases of CSEP presented to us in MOSC Medical College Hospital, Kolenchery during the last 7 months' time from March 2014 to September 2014 are reported.

CASE NO 1: $G_{2} P_{1} L_{1}$ first pregnancy LSCS done 31/2 years back. Seen in the local hospital with two episodes of bleeding following 7 weeks of amenorrhoea. TVS revealed gestational sac in the lower uterine segment with no foetal pole. With a diagnosis of missed abortion, medical management was given but it failed. They did a suction evacuation on the $5^{\text {th }}$ day. During evacuation there was heavy bleeding and follow up USG after 1 week showed echogenic mass with high vascularity in the lower uterine segment and $\beta$ HCG titre was 90,710 IU. She was referred to higher centre but she turned up 3 weeks later to our hospital. At the time of admission she was stable. $\mathrm{P} / \mathrm{V}$ examination revealed bleeding from the os with normal sized uterus, $\beta$ HCG titre was 3354 IU.

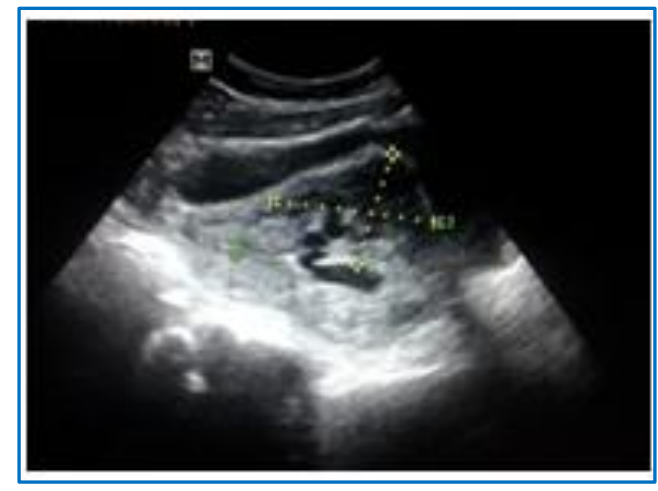

Fig. 1: vascular heteroechoic lesion in the lower endometrium 


\section{CASE REPORT}

TVS showed heteroechoic vascular lesion of 7 x $3.7 \mathrm{~cm}$ with multiple cystic spaces involving anterior lower endometrium and myometrium.

With history of bleeding persisting for 1 month after D\&E and raised $\beta$ HCG and a provisional diagnosis of invasive mole was made and started on MTX/folinic acid rescue regime. Methotrexate 50 $\mathrm{mg}$ I/V alternating with folinic acid $15 \mathrm{mg} \mathrm{I} / \mathrm{V}$ for 8 days repeated 2 weeks later. Follow up $\beta \mathrm{HCG}$ values were regressing (Table 1 ). She received 3 courses of Methotrexate.

\begin{tabular}{|c|c|}
\hline WEEKS & $\boldsymbol{\beta H C G ( I U / m l )}$ \\
\hline 0 & 3354 \\
\hline 2 & 283 \\
\hline 4 & 60.12 \\
\hline 6 & 50 \\
\hline 8 & 21.5 \\
\hline 11 & 2.5 \\
\hline \multicolumn{2}{|c|}{ Table 1: Showing $\beta$ HCG regression }
\end{tabular}

Repeat USG showed highly vascular echogenic mass at the lower uterine segment with low $\beta$ HCG value. So the case was reviewed and a rediagnosis of scar site ectopic was made. She was followed up with $\beta$ HCG and USG. 3 months after starting therapy $\beta$ HCG came to normal, but the mass was persisting but vascularity reduced by 5 months' time (Fig. 2).

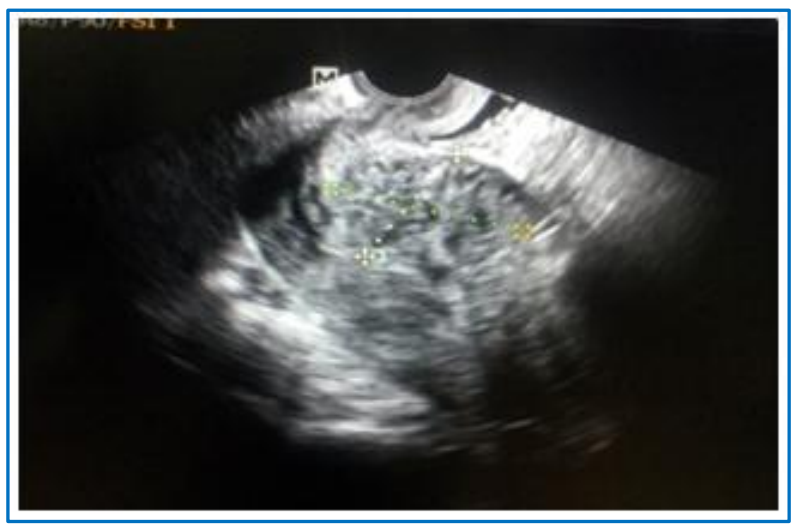

\section{Fig. 2: USG showing residual scar site ectopic mass}

She is still under follow up.

CASE NO 2: $\mathrm{G}_{4} \mathrm{P}_{1} \mathrm{~L}_{1} \mathrm{~A}_{2}$. She had 2 abortions which were managed by D\&E. $3^{\text {rd }}$ pregnancy LSCS done $2 \frac{1}{2}$ years back. Reported to local hospital with 2 episodes of bleeding following 2 months of amenorrhoea. USS revealed $23 \mathrm{~mm}$ sac with live foetus showing regular cardiac activity just above the cervical canal. No definite myometrium seen on lateral aspect. The main uterine cavity showed fluid collection. 


\section{CASE REPORT}

MRI revealed bulky uterus with well-defined gestational sac seen in the lower uterine segment measuring $50 \times 30 \times 35 \mathrm{~mm}$ with anteriorly developing placenta and single embryo of size 16 $17 \mathrm{~mm}$. Cervical canal separately visualized posterior to gestational sac (Fig. 3).

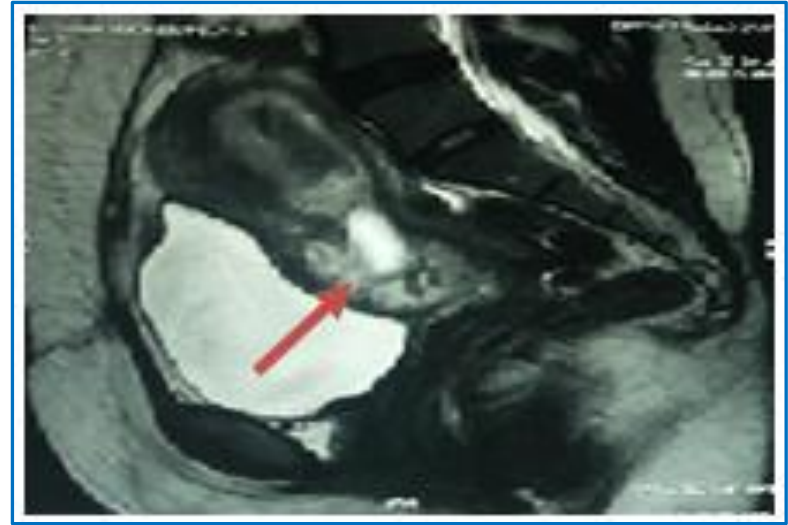

Fig. 3: MRI arrow showing scar site ectopic

She was referred to our hospital. The diagnosis was definite in this case. Since it was a live foetus, we decided to manage with systemic chemotherapy and local $\mathrm{KCl}$ injection into sac.

Trans vaginal ultrasound guided aspiration of amniotic fluid done and $2 \mathrm{ml}$ of $\mathrm{KCl}(4 \mathrm{mEq})$ injected into sac (Fig. 4).

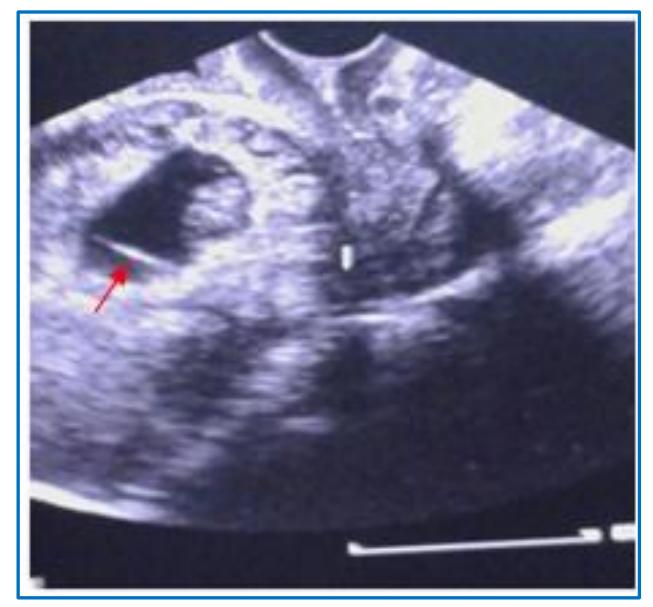

Fig. 4: Needle tip at the amniotic sac (arrow)

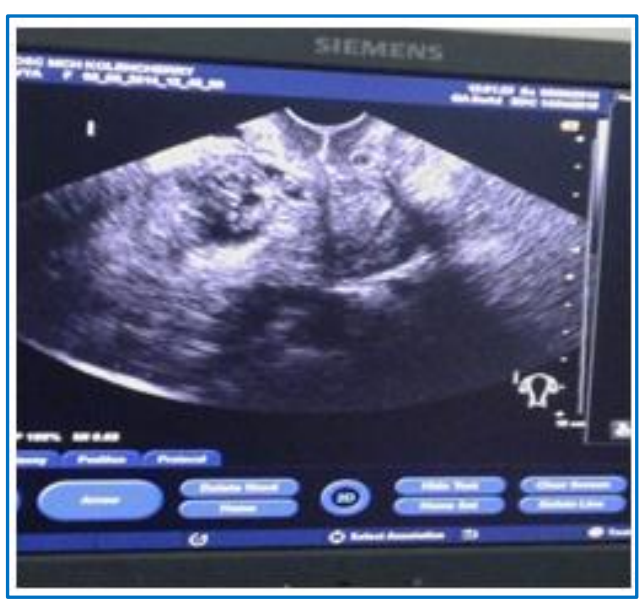

Fig. 5: Post KCl injection with crumbled sac

We could see the FH disappearing with $\mathrm{KCl}$ injection (Fig. 5). MTX / folinic acid rescue regime started the next day after doing basic blood investigation. She was followed up with $\beta$ HCG and USG. Follow up ultrasound revealed heteroechoic mass with peripheral vascularity. She received 2 courses of methotrexate at 2 weeks interval. 3 months after starting chemotherapy $\beta$ HCG became normal (Table 2) and mass reduced considerably in size with no vascularity in 5 months' time (Fig. 6). 


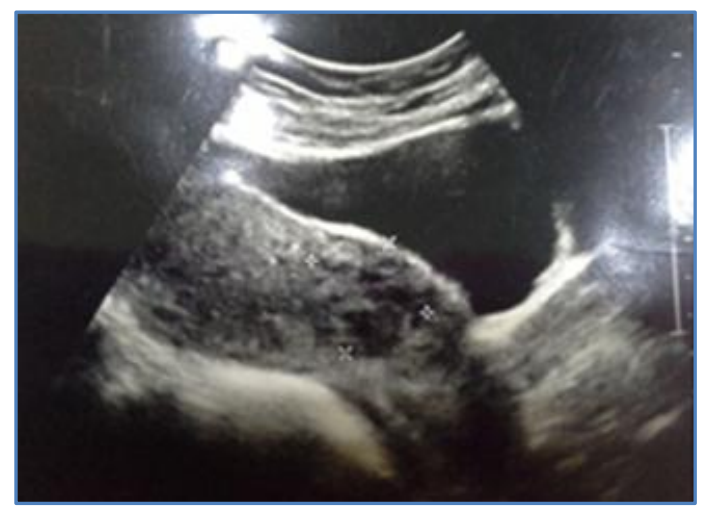

\section{Fig. 6: TVS showing residual ectopic mass}

\begin{tabular}{|c|c|}
\hline WEEKS & $\boldsymbol{\beta H C G ( I U / m l )}$ \\
\hline 0 & 67,598 \\
\hline 1 & 39,585 \\
\hline 2 & 3028 \\
\hline 3 & 436 \\
\hline 4 & 176 \\
\hline 6 & 74 \\
\hline 10 & 2.39 \\
\hline \multicolumn{2}{|c|}{ Table 2: Showing $\beta$ HCG regression } \\
\hline
\end{tabular}

DISCUSSION: CSEP is one of the rarest forms of ectopic. Recent series estimate the incidence of 1 in 2226 of all pregnancies with a rate of $0.15 \%$ in women with caesarean section and rate of $6.1 \%$ of all ectopic in woman who had atleast one caesarean delivery. ${ }^{[2]}$ Incidence does not appear to correlate with number of caesarean. Adenomyosis, IVF pregnancy, previous D\&E, manual removal of placenta are risk factors.

The diagnosis of CSEP is challenging. Clinical presentation ranges from vaginal bleeding with or without pain to uterine rupture and hypovolemic shock. ${ }^{[3]}$ Diagnosis is made by sonographically visualising enlarged scar with an embedded mass. USS criteria for diagnosing CSEP include.[4]

1. Uterus empty with clearly demonstrable endometrium.

2. Clearly visible empty cervical canal without contact with the sac.

3. Presence of gestational sac with or without foetal pole or cardiac activity in the anterior pole of isthmus.

4. Absence or defect in myometrial tissue between bladder and sac.

TVS is considered as first line imaging modality for diagnosis and evaluation with a sensitivity of $84.6 \%$. MRI now provide a more detailed image of tissue. ${ }^{[5]}$

In our first case she had D\& E earlier and reported to us almost 1 month later with irregular bleeding and raised $\beta$ HCG values. The diagnosis was not made initially. Awareness of this rare entity SCAR ECTOPIC and considering it as differential diagnosis is important in early management of the same. 
The immediate complication of CSEP is uterine rupture, severe bleeding and need for hysterectomy and maternal morbidity. If pregnancy continues the risk of placenta accreta is increased up to 3-5 fold.[6] Treatment depends upon the gestational age at presentation, need for future fertility and the general condition of the patient at presentation. The presence of large number of management options tells you there is no standardized protocol for CSEP management.

Management options are medical, surgical and a combination of both methods. Medical treatment preferred for asymptomatic patients with gestational age less than 8 weeks, myometrial thickness less than $2 \mathrm{mms}$ between gestational sac and bladder.[7] Medical treatment include Methotrexate systemically or local injection of $\mathrm{MTX} / \mathrm{KCl}$ into sac. One dose of MTX may not be sufficient. Since placental implantation occurs mainly on fibrous tissue absorption of gestational sac is extremely slow. It takes around 4-16 weeks for $\beta$ HCG to become normal and ectopic mass to disappear.[8]

In our cases the first one had some intervention like D\&E and delay in starting chemotherapy. It took 3 months for $\beta$ HCG to become normal, 6-7 months for ectopic mass to disappear. $2^{\mathrm{ND}}$ case where combined systemic and local therapy was instituted less number of MTX therapy required and early disappearance of ectopic mass noted.

Combination of Mifepristone $200 \mathrm{mg}$ initially followed by Methotrexate tried in one case (Srinivas et al) and they reported successful pregnancy 18 months later. ${ }^{[9]}$ B/L hypogastric ligation associated with trophoblastic evacuation, selective uterine artery embolisation and combination with curettage and MTX administration have been attempted.

Laparotomy followed by wedge resection of lesion should be considered in women who don't respond to conservative medical/surgical treatment or who present late.[10] This seems to be the best option because excision of old scar avoids the possibility of leaving residual trophoblast thereby reducing recurrence.[10]

Huang et al describes new technique for managing CSEP with high intensity focused ultrasound (HIFU) combined with dilatation and curettage.[11] Through HIFU coagulation necrosis of target tissue is achieved by instantaneous temperature elevation to $60-100{ }^{\circ} \mathrm{C}$.

CONCLUSION: Awareness of CSEP and early diagnosis by means of transvaginal sonography improves outcome since it allows more treatment options and avoids danger of haemorrhage and uterine rupture. In women with previous caesarean section early USS should be performed in the subsequent pregnancies to establish location of implantation. Meticulous repair of uterus during caesarean is mandatory in prevention of CSEP, since genesis of scar ectopic is thought to be due to microscopic tract or dehiscence in the previous scar.

\section{REFERENCES:}

1. Urkovie D, Hillaby K, Woelfer B, Lawrence A, Salim R, et al (2003) First trimester diagnosis and management of pregnancies implanted into the lower uterine segment caesarean section scar. Ultrasound Obstet Gynecol 21: 220-227.

2. Gozdemir E, Simavli S 2014 caesarean scar pregnancy: Diagnosis and treatment. J Nurse Care 3: 182. doi 10.4172/2167-1168.1000182, vol 3 issue 4. 1000182.

3. Silver RM, Landon MB, Rouse DJ, Leveno KJ, Spong CY, et al. (2006) Maternal Morbidity associated with multiple repeat caesarean deliveries. Obstet Gynecol 107: 1226-1232. 


\section{CASE REPORT}

4. Fylstra DL (2002) Ectopic pregnancy within a caesarean scar: A review. Obstet Gynecol Surv 57: 537-543.

5. Wu R, Klein MA, Mahboob S, Gupta M, Katz DS (2013) Magnetic resonance imaging as an adjunct to ultrasound in evaluating caesarean scar ectopic pregnancy. J Clin Imaging Sci 3: 16.

6. Ash A, Smith A, Maxwell D (2007) caesarean scar pregnancy. Br J Obstet Gynecol: 253-263.

7. Weimin W, Wenqing L (2002) Effect of early pregnancy on a previous lower segment caesarean section scar. Int J Gynecol. Obstet 77: 201-207.

8. Seow KM, Huang LW, Lin YH, Lin MY, Tsai YL, et al. (2004) Caesarean scar pregnancy: issues in management ultrasound Obstet Gynaecol 2004; 23: 247-253.

9. Srinivas M, Raghupathy K, Ndumbe F (2014): Dilemma in the management of caesarean scar pregnancy. Reprod Syst Sex Disord 3: 125. Doi 10.4172/2161-038x.1000125).

10. Fylstra DL, Pound-Chang T, Miller MG, Cooper A, Miller KM (2002), Ectopic pregnancy within a caesarean delivery scar: A case report Am J Obstet Gynaecol 187: 302-304.

11. Huang L, Du Y, Zhao C (2014) High-intensity focused ultrasound combined with dilatation and curettage for Caesarean scar pregnancy. Ultrasound Obstet Gynecol 43: 98-101.
AUTHORS:
1. Mini Isac
2. Mary George
3. V. M. Jayasree Thankachi

\section{PARTICULARS OF CONTRIBUTORS:}

1. Professor, Department of Obstetrics \& Gynaecology, MOSC Medical College, Kolenchery.

2. Associate Professor, Department of Obstetrics \& Gynaecology, MOSC Medical College, Kolenchery.

\section{FINANCIAL OR OTHER} COMPETING INTERESTS: None
3. Professor \& HOD, Department of Obstetrics \& Gynaecology, MOSC Medical College, Kolenchery.

\section{NAME ADDRESS EMAIL ID OF THE} CORRESPONDING AUTHOR:

Dr. Mini Isac,

Professor of Obstetrics \& Gynaecology, MOSC Medical College, Kolenchery.

E-mail: drminiisac@gmail.com

Date of Submission: 02/02/2015.

Date of Peer Review: 03/02/2015.

Date of Acceptance: 20/02/2015.

Date of Publishing: 02/03/2015. 